\begin{tabular}{cc}
\hline International Journal of Engineering \& Technology, $7(3.14)(2018) 477-480$ \\
SPC \\
Website: $\frac{\text { www.sciencepubco.com/index.php/IJET }}{\text { Research paper }}$ \\
\hline
\end{tabular}

\title{
Innovative Approaches Towards the Formation of Contractual Terms within the Effective System of Risk Management in Foreign Economic Activities
}

\author{
Natalia Vladimirovna Maslennikova ${ }^{1}$, Aleksandr Viktorovich Kravchenko ${ }^{1}$, Artur Abdulxamidovich Orazaliev ${ }^{1}$, \\ Ella Valentinovna Yakubova ${ }^{1}$, Ludmila Vladimirovna Slavnetskova ${ }^{2}$
}

1North Caucasus Federal University (NCFU), 1, Pushkin street, Stavropol, Russia, 355009

2 Yuri Gagarin State Technical University of Saratov (SSTU), 77, Politechnicheskaya street, Saratov, Russia, 410054

\begin{abstract}
The category of contractual risk is considered, which enables to effectively manage activity on the product market in the conditions of scenario uncertainty as well as to evaluate economic feasibility of legal constructions and means of the legal arsenal. In the article the importance of the system risk management in carrying out foreign economic activity is justified. The classification of risks in foreign trade is related consistently and in details. The analysis of innovative approaches towards the formation of contractual terms within the effective system of risk management is of particular interest. Incoterms 2010 was selected as a founding document in contractual terms, thus, a detailed practice of the choice of appropriate basic terms of delivery is presented. A structure of foreign trade prices and factors affecting it are provided for the justification of the selected terms. At the modern stage a system of risk management allows ensuring not only national security of the state but also enables to establish partnership relations with the participants of foreign trade activity that are based on the principle of categorizing, in accordance with which an automatic technology of categorizing the participants of foreign trade activity is developed.
\end{abstract}

Keywords: a system of risk management, contractual terms, foreign trade activity, delivery terms, Incoterms 2010

\section{Introduction}

Modern international trade is developing extremely rapidly, gradually involving more and more countries into transactional trade unions and, thus, affecting the development of national economies of particular states. It becomes evident that at the stage of the development of modern trade-economic relations countries face a serious problem associated with their normative legal regulation and with defining responsibility of the parties in case so called trade risks at any stage of implementing international contracts.

\section{Problem Statement}

In the process of organizing trade relations foreign economic activity participants should have a full understanding of the possible external economic risks, which means to know their classification according to various elements and attributes in order to develop optimal and effective methods and tools of their management as well as mechanisms for their minimization [1]. Enterprises operating on the world market are most vulnerable to environmental factors (Fig.1)

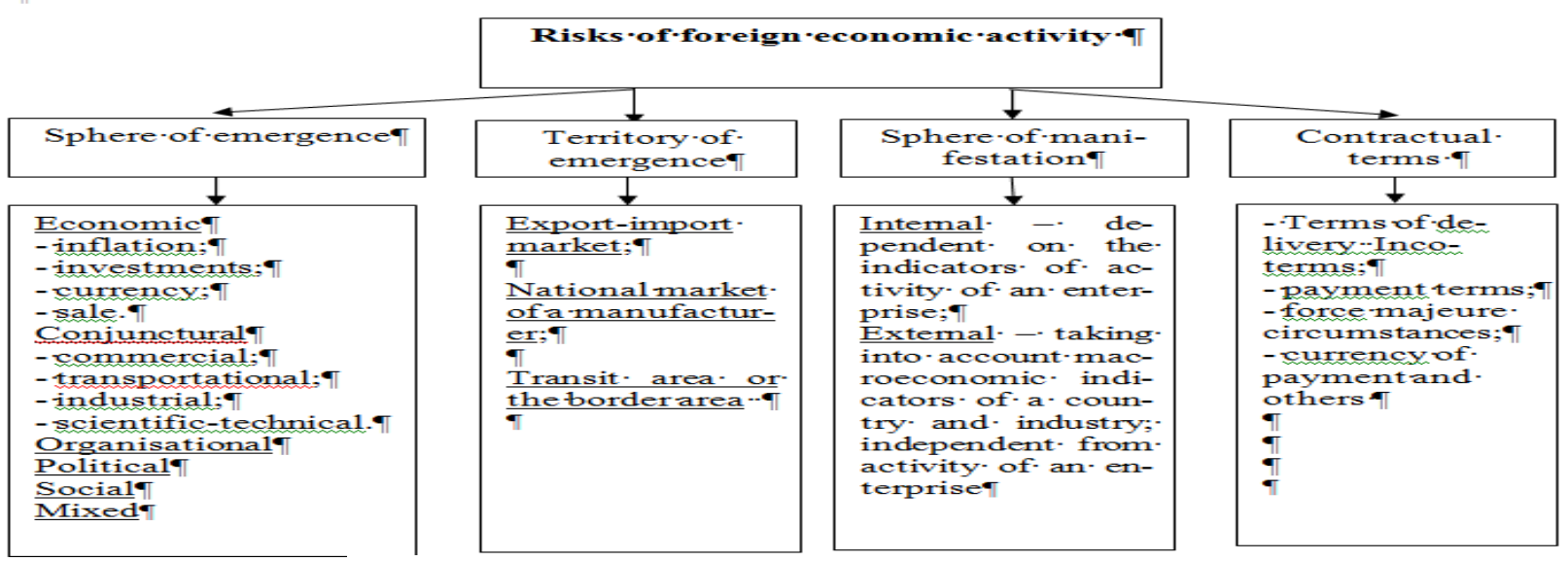

Fig.1. Types of risks in the process of a manufacturer's entering a foreign market. 


\section{Research Results}

A bigger part of risks on the international market will be associated with unscrupulous contractors and with a low level of research on the consumer market. Taking into account these factors will enable to reduce the probability of their emergence and, possibly, to minimize economic damage; however, the selected terms of delivery according to Incoterms 2010 are becoming a most significant factor [2].

The field of application of the given document is limited by those issues that are primarily associated with the rights and responsibilities of the parties of the sales contract in respect of the delivery of the goods sold and only in certain aspects. At present Incoterms 2010 rules are implemented in the process of concluding almost every second international contract. Such popularity is due to the fact that these rules cover all necessary commercial and legal issues in relation with actual executing a foreign trade contract these issues are of particular interest including a place and time of performing the duties of the seller (exporter) in transferring the goods, transition of risks from the exporter to the importer, distributing responsibilities in paying necessary expenses including payment of customs duties and taxes, obtaining export and import licenses and other permissive documentation [3].

In the process of the study of the content of Incoterms 2010 it is advisable to consider the main notions, which are presented as a set of rules (abbreviations) and that define rights and responsibilities of every party of an international sales agreement. The given notions are denoted through abbreviations, which consist of three Latin letters, where each letter symbolizes exactly that time and place, where obligations are transferred from the exporter to the importer.

For a clearer description and presentation of each notion of Incoterms 2010 it is advisable to consider the main basic delivery terms, using an example of a manufacturer, which specializes in the field of agriculture and acts as an importer, and a foreign supplier, for instance, as a seller (exporter) of fertilizers [4].

In this case, if the seller and the buyer select Ex Works, in the concluded contract of an international sales transaction the responsibility of an exporter to carry out delivery will be included that consists in placing the goods at the buyer's disposal in the seller's own premises, for instance, in a warehouse or in a temporary storage warehouse, at the enterprise or in any previously arranged location. It is worth noting that the seller is not obliged to load goods into a vehicle or to carry out any actions associated with transporting goods.

If FCA or Free Carrier terms are selected, a foreign trade contract will include the seller's responsibility to transfer fertilizers to the buyer or to an authorized agent (for instance, an official representative of the agricultural enterprise). In doing so, the transfer is carried out directly in warehouses or in any other previously arranged locations of the seller. In this case counterparties are obliged to determine a place of delivery since in this location all risks of the seller will be transferred to the buyer.

In case the manufacturer does not have a financial opportunity to organize international transportation, it can offer the counterparty to choose a basic term of delivery, which is CPT (Carriage Paid to). It consists in cargo transfer from the seller to an international shipping agent or to an authorized agent, which is done in a previously arranged location. It is important to note that a cargo exporter, according to that rule, is obliged to prepare an agreement of international transportation independently and in advance and to take responsibility for all expenditure connected with delivery of fertilizers to destination [5].

Enterprises choose a basic term CIP (Carriage and Insurance Paid to) quite often. According to it, the fertilizers suppliers is obliged to transfer cargo to the transportation company or any other authorized agent in a previously arranged location. Moreover, the seller is obliged to conclude a transportation contract and to defray the transportation costs. Besides, a vendor company takes the responsibility to conclude an insurance contract, which will cover all the risks emerging due to loss or damage that can be causes during transportation, for example, as a result of defective package. If a contract includes DAT (Delivered at Terminal) term, the supplier is obliged to make delivery only when goods, which were unloaded from a vehicle, are transferred in a previously arranged terminal. It is important to note that this rule covers absolutely every location listed below [6]:

- a container area on the territory that belongs to the manufacturer;

- a warehouse or other building that is mentioned in a contract.

The rule mentioned above also includes responsibility of the seller (exporter) for goods delivery and unloading.

Choosing DAP (Delivered at Place) term, the supplier takes immediate responsibility for delivering goods to the location of the enterprise (customer).

The responsibility for all risks in the process of loading, transporting, unloading is taken by the seller.

If the enterprise does not have an opportunity for DDP (Delivered Duty Paid), the Incoterms 2010 rule, within which cargo delivery done by the seller must include customs clearance of transported goods that is the payment of all necessary customs duties and taxes. All risks associated with transportation as well as with compliance with customs formalities are taken by the vendor company.

As was noted above, the second group of Incoterms 2010 rules id devoted to water transport, which carries goods and cargo over long distances within sea and river space. Speaking of the example provided above, it is worth noting that an enormous amount of fertilizers are imported from countries that are several thousand kilometers from the location of agricultural enterprise-customer, therefore, it is advisable and cheaper to use water transport services.

For instance, the choice of a basic term FAS (Free alongside Ship) means that the fertilizers supplier will implement the commitments only when the goods are placed alongside a ship, at the pier on the territory of a sea or river port, which is determined in an international trade agreement. At that very moment all risks are transferred from the exporter to the importer.

If contractors agree to FOB (Free on Board) term, the fertilizers seller takes responsibility for delivering cargo on board a vessel that was determined in the contract by the buyer on the territory of a port determined by the agricultural manufacturer.

If CFR (Cost and Freight) term is selected, the fertilizers supplier is obliged to deliver cargo on board a sea or river vessel, and as soon as goods are on board a vessel, all risks are transferred from the seller to the customer.

It is important to note that all expenses associated with loading cargo on board a vessel and with delivery to the arranged location are covered by the seller in full.

However, if a foreign trade agreement includes CIF (Cost Insurance and Freight) term, the fertilizers supplier is obliged to deliver cargo on board a vessel. At the moment when goods are on board a vessel, the risks of damage or loss are transferred. As in the previous rule, the exporter is obliged to cover all expenses connected with cargo loading, delivery to the arranged location as well as insurance expenditure in case of different risks.

For instance, if the exporter aims at minimizing the obligations to the customer, it is better to use EXW, FAS or FOB basic terms.

If the importer is interested in placing maximal commitments on the exporter, such group D term as DDP, DAT or DAP should be selected.

Considering the most appropriate options in terms of delivery for a company that specializes, for example, in agriculture, it is worth noting that in some cases group $\mathrm{E}$ or $\mathrm{D}$ terms are selected.

At the same time EXW term requires the exporter to deliver cargo (agricultural products) when it is transferred to the buyer (importer). The considered basic term does not necessarily mean the seller's strict obligation to load goods to a vehicle or to comply with particular formalities associated with delivering goods to the buy- 
er's location. However, according to EXW terms, all risks and expenses in obtaining goods are strictly placed on the importer. Consequently, it is evident that the seller's obligations are minimal.

Nonetheless, according to DAP term the seller is obliged to conclude an international transportation agreement and to deliver goods directly to the destination determined by the buyer. That means that a large part of major risks is taken by the seller. Considering DAP term, it is evident that the seller is obliged to transport goods to a terminal determined in the contract. If the buyer did not indicate a particular terminal for some reason, the seller has the right to choose destination independently with regard to saving delivery time and expenses.
Thus, comparing groups $\mathrm{E}$ and $\mathrm{D}$ of delivery terms Incoterms 2010, we can state that if group D terms are selected, an enterprise (buyer) economizes on delivery of goods bought but, on the other hand, it has to cover additional expense (according to Table 1). If EXW terms are selected, an enterprise (buyer) is obliged to export goods on its own and to accept all transportation risks and expenses. Consequently, if an agricultural enterprise does not have opportunity to arrange international transportation on its own, it is most advisable to choose one of group D terms [7].

It is necessary to mention an important aspect of international Incoterms rules concerning the structure of foreign trade price for every basic delivery term (Table 1) [8].

Table 1. Pricing system with regard to basic delivery terms.

\begin{tabular}{|c|l|}
\hline Goods delivery basis & \\
\hline EXW & Production cost + exporter's profit + preparing goods shipment \\
\hline FCA & EXW price + expenses for goods delivery to a major transporter + customs charge \\
\hline FAS & $\begin{array}{l}\text { EXW price }+ \text { customs charge }+ \text { expenses for delivering goods to a port of shipment }+ \text { expenses for unloading goods in a } \\
\text { port }\end{array}$ \\
\hline FOB & FAS price + expenses for loading goods on board a vessel + expenses for a vessel's service in a port \\
\hline CFR & FOB price + freight costs \\
\hline CIF & CFR price + insurance costs \\
\hline CPT & FCA price + costs of delivery of goods to the border \\
\hline CIP & CPT price + insurance costs \\
\hline DAP & CIP price + insurance costs \\
\hline DAT & CPT price + expenses for unloading goods from a vehicle \\
\hline DDP & CPT price + export/import expenses \\
\hline
\end{tabular}

Price is a conjunctural market category, which if formed according to supply-demand balancing. However, the following aggregate indicators act as agricultural pricing factors at present:

1. low responsiveness of demand for agricultural products, meaning poor reflexion of price changes on the demand side;
2. high cost of agricultural production with a significant stratification in the structure and level of expenses depending on the region and on type of products (Fig.2).

Incoterms 2010 are an indispensable part of legal regulation in all modern countries, regardless of the national economy level and of the directions in global division of labor.

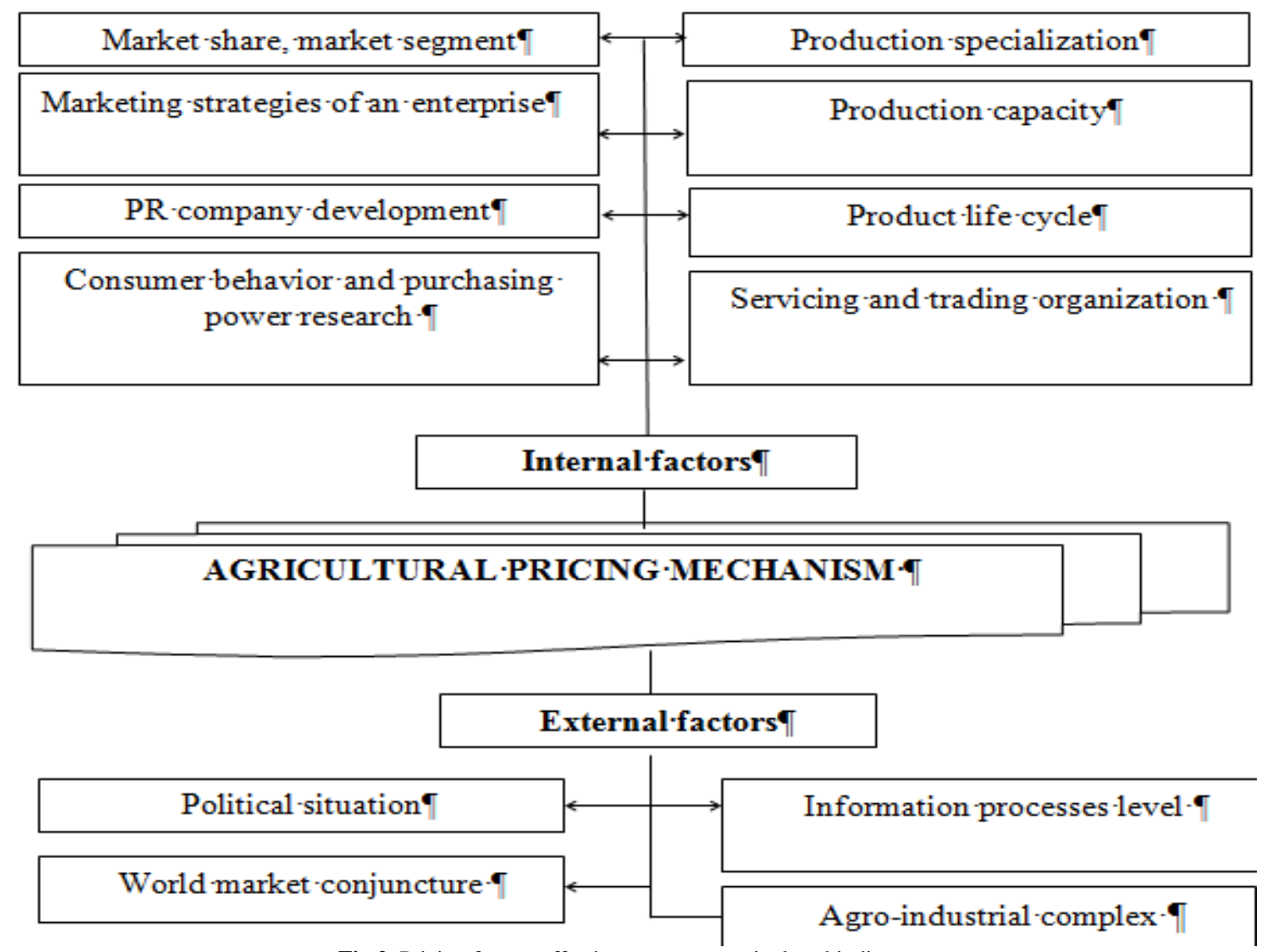

Fig.2. Pricing factors affecting aggregate agricultural indicators. 
The mentioned factors demonstrate the necessity regulate agricultural products prices at the state level. It means the protection of the population from unjustified price increase. On the other hand, it implies the support for agricultural manufacturers (by means of subventions and subsidies) that do not have opportunity for effective functioning due to natural conditions.

While choosing the most appropriate delivery terms, an enterprise (exporter/importer) should focus not only on a contract price, which can be significantly different in each delivery term but also on the interests and risks in each particular foreign trade transaction.
At the same time the use of Incoterms 2010 rules is strictly voluntary and there are almost no cases of its mandatory application. Incoterms 2010 rules are aimed not only at providing rational and correct conclusion of international sales contracts but also at determining responsibilities and rights of every trader. It enables to differentiate between them correctly and to determine each other's responsibility for covering all risks that can occur at any stage of executing an international sale agreement.

Presently customs authorities are the main government institution that is capable to identify and systematize foreign trade risks [9]. The risk management system has been operating since 2004 reducing time for complying with customs formalities (Table 2).

Table 2. The results of implementing automatic technology in categorizing foreign trade participants [10].

\begin{tabular}{|c|c|c|c|}
\hline Year & Разработанные профили рисков & $\begin{array}{c}\text { Кол-во решений об отказе в выпуске } \\
\text { товаров }\end{array}$ & $\begin{array}{c}\text { Кол-во решений о запрете к ввозу или вывозу } \\
\text { товаров }\end{array}$ \\
\hline 2013 & 9379 & 14281 & 578 \\
\hline 2014 & 21612 & 14710 & 10736 \\
\hline 2015 & 35140 & 24304 & 12556 \\
\hline
\end{tabular}

\section{Conclusion}

At the present stage the system of risk management enables to provide not only national security but also to establish partnership relations with foreign trade activity participants basing on the categorizing principle. According to it, automatic technology of categorizing foreign trade participants was developed, which includes full automation of activity assessment and centralized work on risk assessment in the Federal Customs Service [11]. It is possible to conclude with absolute certainty that modern international trade has been developing extremely rapidly for the recent years resulting in establishing its normative-legal base, which content is changed significantly from time to time

\section{References}

[1] Foreign trade activity risks, their classification and means of minimizing. Euro Info Center 2016. http://www.euro-info-center.ru.

[2] N.V. Maslennikova, Ye.N. Kovtun, Creating an effective resistance mechanism against foreign trade security threats in a region, Economics and Management. Problems and Solutions 2(4) (2016) 215-221.

[3] L.I. Ushvitskiy, T.A. Kulagovskaya, A.A. Ter-Grigor'yants, I.V. Solov'yeva, A.A. Babich, The use of multivariate statistical analysis methods in the process of tangible assets assortment optimization, Indian Journal of Science and Technology 9(16) (2016) 892-896.

[4] L.I. Ushvitskii, T.A. Kulagovskaya, A.A. Ter-Grigor'yants, I.V. Solovyova, E.S. Mezentseva, Methodological tools for risk assessment in industrial enterprises, International Journal of Economics and Financial Issues 5(4) (2015) 1011-1016.

[5] M.A. Sirotinina, Classification of threats to Russia's economic security in the foreign trade sphere, Moscow, 2011.

[6] Ye.M. Kondratyeva, M.S. Gorina, Legal aspects of managing foreign trade contractual risks, The Bulletin of Lobachevsky State University of Nizhni Novgorod 2 (2015) 117-125.

[7] D.I. Fayzrakhmanov, L.F. Khazeev, Risks associated with innovations and investments in the agro-industrial complex, The Bulletin of Kazan State Agrarian University 11(3) (2016) 107-113.

[8] A.V. Kravchenko, N.V. Maslennikova, M.G. Rusetskiy, E.N. Kovtun, A.A. Orazaliev, Factor combination of the price for the foreign trade contract and its influence on the international pricing, International Journal of Economic Perspectives 11(2) (2016) 337-344.

[9] Yu.V. Rozhkova, The influence of the customs functions system on the improvement of the customs administering under the integration conditions, Intellect. Innovations. Investments 3 (2017) 43-47. 